\title{
FORMULASI DAN UJI PELEPASAN KRIM EKSTRAK ETANOL DAUN JAMBU BIJI DENGAN POTENSI ANTIJERAWAT
}

\author{
N. P. Y. A. Dewi", N. L. G. W. Pebriani, P. A. Duarsa, P. C. I. Warnaya, \\ I. D. A. A. D. Candraningrat dan C. I. S. Arisanti \\ Program Studi Farmasi, Fakultas Matematika dan Ilmu Pengetahuan Alam \\ Universitas Udayana, Jimbaran, Badung, Bali, Indonesia \\ "Email: yesianita10@gmail.com
}

\begin{abstract}
ABSTRAK
Daun jambu biji mengandung kuersetin yang dapat menghambat pertumbuhan bakteri Propionibacterium acne. Hal ini menyebabkan daun jambu biji berpotensi sebagai anti jerawat. Berdasarkan manfaat daun jambu biji maka perlu dilakukan formulasi ekstrak etanol daun jambu biji menjadi sediaan krim beserta uji karakeristiknya serta mengetahui laju pelepasan sediaan. Dilakukan penyiapan dan standarisasi simplisia daun jambu biji. Setelah itu dilakukan maserasi, standarisasi, dan skrining fitokimia ekstrak etanol daun jambu biji.Ekstrak yang positif mengandung flavonoid diformulasikan menjadi sediaan krim. Dilakukan optimasi konsentrasi asam stearat sebagai emulgator dengan konsentrasi $14 \%$ dan $18 \%$. Formula diuji sifat fisik dan kimia meliputi uji organoleptis, daya sebar, daya lekat, dan viskositas serta uji $\mathrm{pH}$. Formula yang optimum dikarakterisasi dengan uji difusi Franz untuk mengetahui pelepasan zat aktifnya. Hasil penelitian menunjukkan bahwa konsentrasi asam stearat sebagai emulgator mempengaruhi sifat fisika dan kimia sediaan. Formula yang optimum adalah konsentrasi asam stearat 14\% dengan pelepasan zat aktif selama 3 jam sebesar 2,5882 mg.
\end{abstract}

Kata kunci: daun jambu biji, jerawat, krim, asam stearat, difusi

\section{ABSTRACT}

Guava leaves contain quercetin which can inhibit the growth of Propionibacterium acne. Thus, guava leaves have the potential to be anti-acne. Based on the benefits of guava leaves, it is necessary to formulate the ethanol extract of guava leaves in cream preparation and its characterization as well as to know the rate of releasing active substances. Preparation and standardization of guava leaf simplicia was carried out. After that, maceration, standardization and phytochemical screening of guava leaf ethanol extract were done. Positive extracts containing flavonoids were formulated into cream preparation. The concentration of stearic acid as emulgator of $14 \%$ and $18 \%$ was optimized. The formula was tested for physical and chemical properties such as organoleptic, spreadability, adhesion, viscosity and $\mathrm{pH}$. The optimum formula was characterized using Franz. diffusion test to determine the release of the active substance. The results showed that concentration of stearic acid as emulgator influenced the physical and chemical properties of the cream. Based on the results of this study it could be concluded that the optimum formula was stearic acid concentration of $14 \%$ with the release active substances for 3 hours of 2,5882 $\mathrm{mg}$.

Keywords: Guava leaves, acne, cream, stearic acid, diffusion

\section{PENDAHULUAN}

Acne vulgaris atau jerawat merupakan salah satu penyakit kulit yang selalu mendapat perhatian bagi para remaja dan orang dewasa. Jerawat adalah radang kulit akibat adanya peningkatan produksi sebum, keratinosid, dan pertumbuhan bakteri Propionibacterium acne sehingga pori-pori tersumbat (BPOM, 2012). Faktor penyebab jerawat diantaranya faktor genetik, ras, makanan, jenis kulit, iklim, dan penggunaan kosmetik (Saragih et al., 2016).

Jerawat umumnya muncul pada para remaja perempuan ataupun laki-laki. Prevalensi tertinggi terjadinya jerawat yaitu pada perempuan berusia 14-17 tahun berkisar $83-85 \%$ dan pada laki-laki berkisar 95-100\%. Tingginya prevalensi penyakit jerawat mendorong industri kosmetik kecantikan untuk menciptakan produk yang dapat mengatasi masalah jerawat. 
Pengobatan jerawat dapat dilakukan dengan terapi topikal maupun oral (Aqsha et al., 2016).

Produk kosmetik yang telah beredar saat ini sebagian besar mengandung zat aktif dari bahan alam. Salah satu bahan alam yang memiliki aktivitas antibakteri adalah daun jambu biji. Antijerawat alami dari daun jambu biji dengan kandungan quersetin. Menurut penelitian Afifi dan Erlin. (2017) ekstrak daun jambu biji dapat menghambat pertumbuhan bakteri Propionibacterium acnes dengan kadar hambat $25 \mathrm{mgmm}^{-1}$. Produk kosmetik antijerawat dapat dibuat dalam bentuk sediaan krim. Krim adalah sediaan semisolid (setengah padat) yang mengandung satu atau lebih bahan obat terlarut dalam bahan dasar yang sesuai (Depkes RI, 1995). Sediaan krim memiliki banyak kelebihan, seperti mudah digunakan, tidak lengket, mudah dicuci, bentuk sediaan lebih menarik dan nyaman digunakan (Ansel, 2008). Oleh karena itu, perlu dilakukan penelitian mengenai formula dan quality control sediaan semisolid berbahan dasar daun jambu biji (Psidium guajava) sehingga dapat memenuhi persyaratan dan menjamin mutu sediaan.

\section{MATERI DAN METODE}

\section{Bahan}

Bahan yang digunakan pada penelitian ini yaitu daun jambu biji yang diperoleh dari Desa Pelaga, Petang, Badung-Bali, etanol $96 \%$ (Bratachem), asam stearat (Bratachem), gliserin (Bratachem), trietanolamin (Bratachem), setil alkohol (Bratachem), parafin (Bratachem), metil paraben (Bratachem), propil paraben (Bratachem), aquadest (Bratachem), kloroform (Bratachem), asam klorida encer LP (larutan pereaksi) (Bratachem), pereaksi dragendroff, pereaksi mayer, serbuk magnesium, $\mathrm{HCl}$ (Bratachem), etil asetat (Bratachem), asam formiat (Bratachem), asam asetat (Bratachem), plat KLT Silika Gel 60 F254.

\section{Alat}

Alat yang digunakan diantaranya timbangan analitik (Adam AFP-360L), blender (Philips), oven (Binder), pipet tetes, ViscometerBrookfield DV-E, pH-meter digital (Mettler Toledo), vacuum rotary evaporator (Eyela), Hot plate (Corning PC-420D), alat uji kadar abu (Wise Therm), penangas air (Memmert), kertas perkamen, mortir, stemper, sendok tanduk, cawan porselen, kertas saring, mikroskop, batang pengaduk, bejana maserasi, gelas objek, kaca bening, plastik mika, vial, dan alat-alat gelas (Pyrex).

\section{Cara Kerja \\ Penyiapan Simplisia}

Daun jambu biji yang digunakan yaitu daun yang tidak terlalu muda dan tidak terlalu tua.Daun dikumpulkan dan dicuci pada air mengalir untuk menghilangkan kotoran yang menempel pada permukaan daun dan dijemur pada sinar matahari langsung dengan bagian atas ditutupi kain hitam selama 4 hari kemudian dilanjutkan pengeringan menggunakan oven pada suhu $40^{\circ} \mathrm{C}$ hingga hari ke-5. Setelah kering, daun diblender lalu diayak dengan ayakan no.30 hingga diperoleh serbuk simplisia daun jambu biji dengan derajat kehalusan tertentu (Juliantoni dan Murford, 2013). Gambar 1 menunjukkan makrokopis serbuk daun jambu biji.

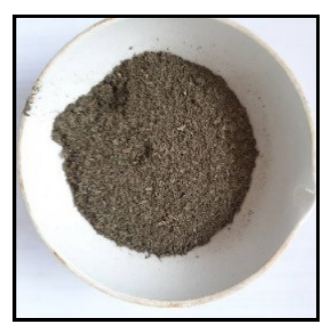

Gambar 1. Makroskopis Serbuk Daun Jambu Biji

\section{Standarisasi Simplisia}

Standarisasi simplisia dilakukan uji organoleptis makroskopik dan mikroskopik, uji kadar sari larut air, uji kadar sari larut etanol, dan susut pengeringan sesuai dengan Farmakope Herbal Indonesia.

\section{Ekstraksi Daun Jambu Biji}

Ekstraksi dilakukan dengan metode maserasi menggunakan pelarut etanol 96\%.500 gram serbuk simplisia dimasukkan ke dalam toples kaca yang telah diberi lakban hitam, pelarut etanol 96\% dimasukkan hingga simplisia tersebut terendam seluruhnya.Diamkan selama $3 \times 24$ jam, sambil sesekali diaduk.Setelah 3 hari, maserat dikeluarkan dan ditampung. Remaserasi dilakukan selama 3 hari hingga maserat menjadi jernih.Hasil penampungan pelarut dicampurkan kemudian dilakukan pemekatan ekstrak menggunakan alat vacuum rotary evaporator dilanjutkan dengan water bath pada suhu $70^{\circ} \mathrm{C}$ (Yulianti, 2015). 


\section{Standarisasi Ekstrak}

Standarisasi ekstrak yang dilakukan pada penelitian ini yaitu uji organoleptis, uji kadar abu total, uji kadar abu tidak larut asam, dan uji kadar air sesuai dengan Farmakope Herbal Indonesia.

\section{Skrining Fitokimia}

Skrining fitokimia dilakukan uji flavonoid, uji saponin, uji triterpenoid dan steroid.

\section{Penentuan Kadar Flavonoid Total}

Penentuan kadar flavonoid dilakukan dengan KLT-Spektrodensitometri. Fase gerak yang digunakan adalah etil asetat: asam formiat: asam asetat: air (100:11:11:26) dan fase diam berupa plat KLT Silika Gel $60 \mathrm{~F}_{254}$. Konsentrasi larutan seri 20, 40, 60, 80 dan $100 \mu \mathrm{g} / \mathrm{mL}$. Plat KLT dipotong dengan ukuran 8x10 $\mathrm{cm}$. Penotolan larutan seri, sampel dan standar sebanyak 4 mikro.

\section{Formula Krim}

Formula sediaan krim dengan variasi konsentrasi asam stearat yaitu 14\% dan 18\%.

Tabel 1.Formula Sediaan Krim Ekstrak Etanol Daun Jambu Biji

\begin{tabular}{lcc}
\hline \multicolumn{1}{c}{ Bahan } & $\begin{array}{c}\text { Formula } \\
\mathbf{1}\end{array}$ & Formula 2 \\
\hline $\begin{array}{l}\text { Ekstrak etanol } \\
\text { daun jambu }\end{array}$ & $2,5 \%$ & $2,5 \%$ \\
biji & & \\
Trietanolamin & $2 \%$ & $2 \%$ \\
Asam stearate & $14 \%$ & $18 \%$ \\
Setil alkohol & $1,5 \%$ & $1,5 \%$ \\
Parafin & $25 \%$ & $25 \%$ \\
Gliserin & $3 \%$ & $3 \%$ \\
Propil paraben & $0,02 \%$ & $0,02 \%$ \\
Metil paraben & $0,18 \%$ & $0,18 \%$ \\
Akuades & Sampai & Sampai $50 \mathrm{~mL}$ \\
\hline
\end{tabular}

\section{Pembuatan Sediaan Krim}

Semua bahan yang digunakan ditimbang sesuai dengan perhitungan. Asam stearat, setil alkohol, dan parafin ditempatkan dalam cawan kemudian dilebur diatas penangas air pada suhu $70^{\circ} \mathrm{C}$ (fase minyak). Trietanolamin, gliserin, propil paraben, dan metil paraben ditempatkan dalam gelas beker dan dilebur diatas penangas air pada suhu $70^{\circ} \mathrm{C}$ (fase air). Kemudian fase minyak dan fase air yang telah dilebur dicampur dalam mortir dan digerus dengan kuat hingga terbentuk basis krim. Basis krim ditambahkan sedikit demi sedikit ke dalam ekstrak daun jambu biji sambil digerus hingga terbentuk krim yang homogen.

\section{Evaluasi Sediaan}

Evaluasi sediaan krim dilakukan uji organoleptis, uji homogenitas, uji daya lekat, uji daya sebar, uji $\mathrm{pH}$, uji viskositas, uji tipe krim dan uji difusi.

\section{Uji Difusi}

Uji difusi dilakukan dengan metode sel difusi Franz. Media kompartemen reseptor digunakan akuades $\mathrm{pH}$ 7,4. Kompartemen reseptor diisi dengan akuades $\mathrm{pH}$ 7,4 hingga penuh kemudian dimasukkan magnetic stirrer, suhu dijaga pada $37^{\circ} \mathrm{C}$. Membran diletakkan diantara kompartemen donor dan kompartemen reseptor.Dimasukkan 3 gram krim ke dalam alat uji pada kompartemen donor dan magnetic stirrer dijalankan pada kecepatan 250 rpm.Sampel diambil sebanyak $2 \mathrm{~mL}$ yang dilakukan pada menit ke 15, 30, 60, 120, dan 180 menit. Sampel yang diambil selanjutnya dianalisis dengan menggunakan spektrofotometri UV untuk menentukan kandungan flavonoid total.

\section{HASIL DAN PEMBAHASAN}

Standarisasi adalah proses yang bertujuan untuk menjamin produk akhir agar mempunyai nilai parameter konstan dan telah ditetapkan. Bahan baku yang digunakan harus dilakukan penjaminan mutu secara spesifik dan non spesifik. Hal ini diperlukanagar bahan baku terstandar dan dapat digunakan sebagai senyawa aktif yang konstan serta dapat dipertanggungjawabkan (Depkes RI, 2000). Parameter simplisia dan ekstrak dikatakan terstandar jika memenuhi persyaratan standarisasi yang ada pada FHI (Farmakope Herbal Indonesia) sesuai dengan simplisia yang digunakan. Hasil standarisasi simplisia daun jambu biji dapat dilihat pada Tabel 2. 
Tabel 2. Standardisasi Simplisia Daun Jambu Biji

\begin{tabular}{|c|c|c|c|c|}
\hline No. & Standarisasi & Hasil dalam \% ( \pm SD) & Syarat FHI & Keterangan \\
\hline 1. & Organoleptis & $\begin{array}{l}\text { Hijau, bau khas aromatik, } \\
\text { dan rasa kelat. }\end{array}$ & $\begin{array}{c}\text { Hijau, bau khas } \\
\text { aromatik, rasa } \\
\text { kelat. }\end{array}$ & Memenuhi \\
\hline 2. & Susut pengeringan & $0,85 \% \pm 0,225 \%$ & $<10 \%$ & Memenuhi \\
\hline 3. & Kadar abu total & $0,353 \% \pm 0,1026 \% \mathrm{~b} / \mathrm{b}$ & $<9,0 \%$ & Memenuhi \\
\hline 4. & Kadar sari larut air & $18 \% \pm 0,78 \% \mathrm{~b} / \mathrm{b}$ & $>18,2 \%$ & $\begin{array}{l}\text { Tidak } \\
\text { Memenuhi }\end{array}$ \\
\hline 5. & Kadar sari larut etanol & $30,25 \% \pm 0,94 \% \mathrm{~b} / \mathrm{b}$ & $>18,2 \%$ & Memenuhi \\
\hline
\end{tabular}

Pengukuran parameter susut pengeringan dilakukan untuk mengetahui persentase senyawa yang menghilang selama proses pemanasan. Uji ini bertujuan untuk mengetahui kadar air simplisia. Simplisia belum memenuhi bobot konstan karena selisih persentase susut pengeringan lebih dari $0,25 \%$ dengan persentase susut pengeringan $0,85 \%$. Kadar sari larut air dan etanol pada standarisasi simplisia dilakukan untuk mengetahui kadar sari yang terlarut di dalam pelarut air dan etanol dimana pada simplisia daun jambu biji yaitu $18 \%$ dan $30,25 \%$. Kadar sari larut air belum memenuhi syarat, yaitu masih kurang dari 18,2\%. Kadar abu ada hubungannya dengan mineral suatu bahan. Dilakukannya penetapan kadar abu lebih memudahkan mengetahui jumlah mineralnya melalui pembakaran atau pengabuan. Hal ini disebabkan karena jika mineral ditentukan dalam bentuk aslinya akan sangat sulit. Kadar abu total simplisia sudah mencapai bobot konstan pada penimbangan abu ke-4 sebesar $0,353 \% \quad \pm$ $0,1026 \%$.
Ekstraksi dilakukan dengan metode maserasi yang mana 500 gram daun jambu biji ditambahkan dengan pelarut etanol 96\% (1:3 b/v) pada suhu ruang selama 72 jam. Remaserasi dilakukan sebanyak 1 kali selama 72 jam.Maserat dipisahkan dengan pelarutnya melalui penguapan dengan rotary vacuum evaporator sehingga menghasilkan ekstrak kental. Penelitian ini tidak menentukan sisa pelarut dalam ekstrak dikarenakan sediaan yang akan di buat adalah sediaan topikal. Pengunaan rotary vacuum evaporator ditujukan untuk mempercepat proses pengentalan. Rendemen ekstrak kental yang diperoleh oleh peneliti yaitu $12,65 \%$.

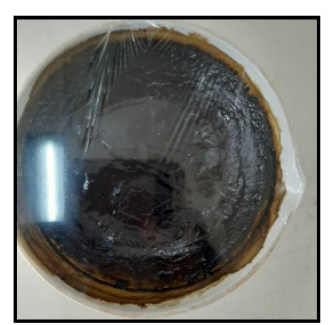

Gambar 2. Ekstrak Kental Daun Jambu Biji

Tabel 3. Standardisasi Ekstrak Etanol Daun Jambu Biji

\begin{tabular}{lllll}
\hline No. & Standarisasi & Hasil $( \pm$ SD $)$ & $\begin{array}{c}\text { Syarat } \\
\text { FHI }\end{array}$ & Keterangan \\
\hline 1 & Kadar air & $23,68 \% \pm 0,00 \% \mathrm{~b} / \mathrm{v}$ & $<10,0 \%$ & Tidak Memenuhi \\
2 & Kadar abu total & $0,083 \% \pm 0,06 \% \mathrm{~b} / \mathrm{b}$ & $<0,8 \%$ & Memenuhi \\
3 & $\begin{array}{l}\text { Kadar abu tidak larut } \\
\text { asam }\end{array}$ & $0,35 \% \% \pm 0,0005 \% \mathrm{~b} / \mathrm{b}$ & $<0,2 \%$ & Memenuhi \\
\hline
\end{tabular}

Standarisasi ekstrak yang dilakukan mencakup kadar abu total, kadar abu tidak larut asam, kadar air, dan penetapan kadar flavonoid total. Hasil standarisasi ekstrak etanol daun jambu biji dapat dilihat pada Tabel 3 yang mana kadar abu total ekstrak mencapai bobot konstan 
pada penimbangan ke-3 sebesar 0,083\% \pm 0,0579\%. Sementara itu, kadar abu tidak larut asam ekstrak mencapai bobot konstan pada penimbangan ke-4 dengan nilai $0,35 \% \quad \pm$ $5,05 \times 10-3 \%$. Kadar abu total ekstrak sudah memenuhi syarat, yaitu tidak lebih dari $0,8 \%$, namun kadar abu tidak larut asam ekstrak belum memenuhi syarat karena lebih dari $0,2 \%$. Kadar air yang diperoleh adalah $23,68 \%$ menunjukkan bahwa ekstrak belum memenuhi syarat kadar air karena memiliki kadar air lebih dari $10 \%$.
Kandungan air yang tinggi dapat menyebabkan ekstrak lebih mudah rusak sehingga diperlukan perlakuan khusus dalam penyimpannya.Air merupakan media pertumbuhan yang baik untuk mikroorganisme karena merupakan komponen terbesar dari sel sehingga penentuan kadar air menjadi penting. Penentuan flavonoid total dilakukan dengan metode KLTSpektrofotodensito dan diperoleh kadar flavonoid sebesar $\quad 19,14 \quad \mu \mathrm{g} / \mathrm{mL}$.

Tabel 4. Skrining Fitokimia Ekstrak Etanol Daun Jambu Biji

\begin{tabular}{|c|c|c|c|c|}
\hline No. & Uji & Hasil & Pustaka & Simpulan \\
\hline 1 & Flavonoid & $\begin{array}{l}\text { Berfluoresensi kuning } \\
\text { intensif di UV } 366 \mathrm{~nm}\end{array}$ & $\begin{array}{l}\text { Terjadi fluoresensi } \\
\text { kuning intensif di sinar } \\
\text { UV } 366 \mathrm{~nm} \text { (Depkes RI, } \\
\text { 1979) }\end{array}$ & + Flavonoid \\
\hline 2 & Saponin & Tidak terbentuk busa & $\begin{array}{l}\text { Buih } 1-10 \mathrm{~cm} \text { selama } 10 \\
\text { menit (Depkes RI,1979) }\end{array}$ & - Saponin \\
\hline 3 & $\begin{array}{l}\text { Steroid } \\
\text { danTriterpenoi } \\
\text { d }\end{array}$ & $\begin{array}{l}\text { Terbentuk cincin } \\
\text { berwarna biru }\end{array}$ & $\begin{array}{l}\text { Terbentuk cincin } \\
\text { berwarna biru }\end{array}$ & + Steroid \\
\hline
\end{tabular}

Skrining fitokimia pada ekstrak etanol daun jambu biji dapat memberikan gambaran mengenai golongan senyawa yang terkandung dalam ekstrak yang digunakan (Kristanti et al., 2008). Berdasarkan hasil pada Tabel 4 diperoleh ekstrak daun jambu biji secara kualitatif positif mengandung flavonoid dan steroid.Quersetin merupakan golongan senyawa flavonoid yang berperan dalam aktivitas farmakologi antijerawat.Penelitian yang dilakukan oleh Murtiningsih et al.,(2014) dan Abdurraafi et al.,(2015) melaporkan bahwa senyawa flavonoid memiliki aktivitas antibakteri terhadap pertumbuhan bakteri $P$. acnes dan $S$. epidermidis.

Tabel 5. Hasil Uji Evaluasi Sediaan Krim Ekstrak Etanol Daun Jambu Biji

\begin{tabular}{|c|c|c|c|c|}
\hline PARAMETER & FORMULA 1 & FORMULA 2 & SYARAT & KETERANGAN \\
\hline Organoleptis & $\begin{array}{l}\text { Warna coklat, } \\
\text { berbau khas, } \\
\text { bentuk semisolid }\end{array}$ & $\begin{array}{l}\text { Warna coklat, } \\
\text { berbau khas, } \\
\text { bentuk semisolid }\end{array}$ & - & Memenuhi syarat \\
\hline $\begin{array}{l}\text { Viskositas dan } \\
\text { rheogram }\end{array}$ & $\begin{array}{l}6840 \text { cPs / } \\
\text { Pseudoplastis }\end{array}$ & $\begin{array}{l}9950 \mathrm{cPs} / \\
\text { Pseudoplastis }\end{array}$ & $4000-40.000 \mathrm{cPs}$ & Memenuhi syarat \\
\hline pH & 7,83 & 7,87 & $4,5-6,5$ & $\begin{array}{l}\text { Belum memenuhi } \\
\text { syarat }\end{array}$ \\
\hline Daya lekat & 1 detik \pm 0 detik & $\begin{array}{l}1,36 \text { detik } \pm 3,4 \times \\
10^{-3} \text { detik }\end{array}$ & $\begin{array}{l}\text { Tidak kurang dari } \\
4 \text { detik }\end{array}$ & $\begin{array}{l}\text { Belum memenuhi } \\
\text { syarat }\end{array}$ \\
\hline Daya sebar & $\begin{array}{l}9,41 \mathrm{~cm}^{2} \pm 0,3 \\
\mathrm{~cm}^{2}\end{array}$ & $\begin{array}{l}7,75 \mathrm{~cm}^{2} \pm 0,11 \\
\mathrm{~cm}^{2}\end{array}$ & $5-7 \mathrm{~cm}^{2}$ & $\begin{array}{l}\text { Belum memenuhi } \\
\text { syarat }\end{array}$ \\
\hline $\begin{array}{l}\text { Tipe emulsi } \\
\text { Difusi }\end{array}$ & $\begin{array}{l}\text { Minyak dalam air } \\
2,5882 \text { mg selama } \\
3 \text { jam }\end{array}$ & Minyak dalam air & Minyak dalam air & Memenuhi syarat \\
\hline
\end{tabular}


Evaluasi sediaan krim yang dilakukan yaitu uji organoleptis, uji $\mathrm{pH}$, uji daya lekat, uji daya sebar, uji viskositas, dan uji difusi.Uji organoleptis dilakukan untuk mengevaluasi sifat fisik sediaan meliputi bentuk, warna, dan bau. Berdasarkan uji yang dilakukan, sediaan berupa sediaan semisolid, berwarna coklat, dan berbau khas daun jambu biji. Semakin tinggi konsentrasi ekstrak akan menghasilkan bau khas daun jambu biji yang semakin meningkat dan warna yang dihasilkan akan semakin pekat.

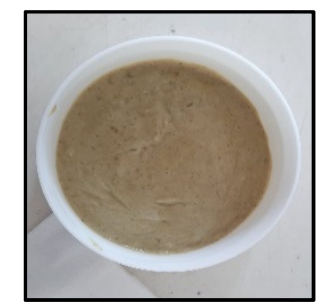

Gambar 3. Krim Ekstrak Etanol Daun Jambu Biji

Uji pH pada sediaan krim dilakukan untuk mengevaluasi $\mathrm{pH}$ sediaan, apakah sudah memenuhi persyaratan yang baik sehingga sediaan tidak mengiritasi kulit ketika digunakan. Berdasarkan hasil pengukuran $\mathrm{pH}$, diperoleh $\mathrm{pH} 7,83$ untuk formula 1 dan 7,87 untuk formula 2. Kedua formula sediaan memiliki $\mathrm{pH}$ yang tidak memenuhi syarat $\mathrm{pH}$ kulit, yaitu 4,5-6,5. $\mathrm{pH}$ sediaan yang terlalu asam dapat menyebabkan timbulnya iritasi kulit, sedangkan $\mathrm{pH}$ sediaan yang terlalu basa dapat membuat kulit menjadi bersisik (Genatrika et al., 2016). Uji daya sebar dilakukan untuk mengetahui kemampuan sediaan krim menyebar pada saat diaplikasikan pada kulit. Berdasarkan hasil yang diperoleh, formula 1 memiliki daya sebar $9,41 \mathrm{~cm}^{2}$, sedangkan formula 2 memiliki nilai daya sebar $7,75 \mathrm{~cm}^{2}$. Kedua formula belum memenuhi syarat daya sebar yang baik, yaitu berkisar 5-7 cm. Semakin tinggi daya sebar maka absorbsi obat ke dalam kulit semakin cepat karena kontak antara kulit dengan obat menjadi luas (Genatrika et al., 2016).

Uji daya lekat dilakukan untuk mengetahui kemampuan suatu sediaan melekat pada bagian tubuh tertentu.Baik formula 1 maupun formula 2, memiliki daya lekat kurang dari 4 detik, sehingga belum memenuhi syarat daya lekat yang baik yaitu tidak kurang dari $4 \operatorname{detik(Genatrika~et~al.,~}$ 2016). Semakin lama waktu lekatnya, semakin lama juga waktu kontak dari zat aktif yang terabsorpsi, begitu pula sebaliknya.

Berdasarkan uji viskositas, rheogram yang dihasilkan diperoleh bahwa sediaan krim, baik formula 1 maupun formula 2 memiliki rheogram pseudoplastis. Viskositas akan meningkat karena penurunan tekanan geser sehingga sediaan akan berbentuk padat saat disimpan dan akan mudah jika dipindahkan atau dikeluarkan dari wadah karena adanya tekanan geser yang menyebabkan viskositas menurun. Kedua formula telah memenuhi syarat viskositas krim yang baik yaitu berkisar antara 40 40.000 cPs (Genatrika et al., 2016). Viskositas formula 2 lebih tinggi dibandingkan formula 1 karena pada formula 2 jumlah asam stearat yang digunakan lebih tinggi.

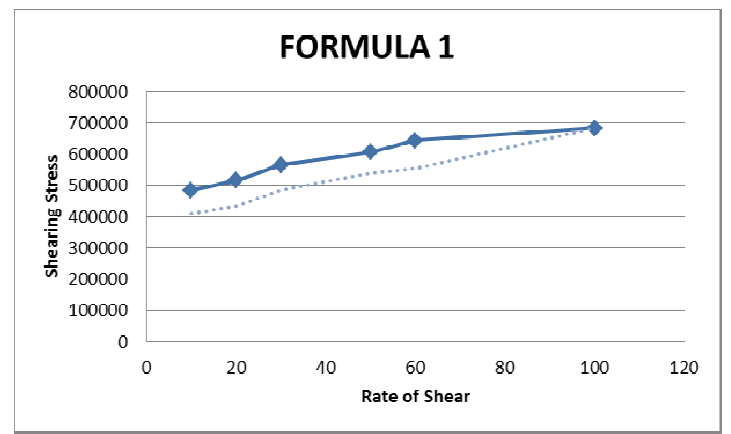

Gambar 4. Rheogram Krim Formula 1

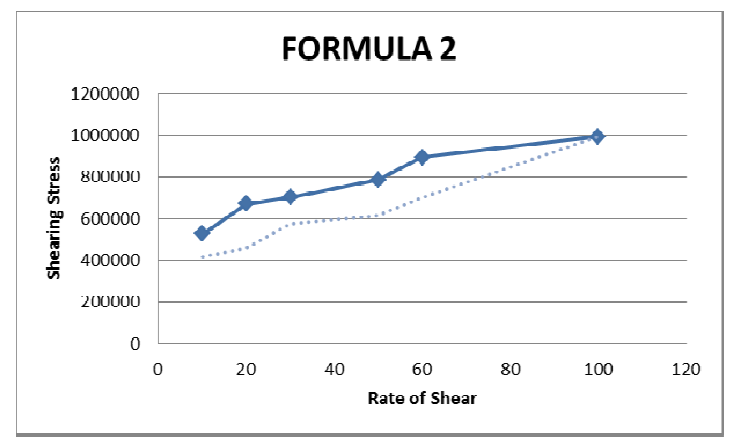

Gambar 5. Rheogram Krim Formula 2 
Uji difusi dilakukan secara in vitro menggunakan sel difusi Franz. Pengujian ini dilakukan untuk mengetahui jumlah zat aktif yang dapat berpenetrasi melalui kulit selama interval waktu tertentu. Diperoleh jumlah flavonoid yang terpenetrasi selama 15, 30, $60,120,180$ menit berturut-turut yaitu $0,6105 \mathrm{mg}, 1,0823 \mathrm{mg}, 1,6491 \mathrm{mg}, 2,2406$ $\mathrm{mg}$, dan 2,5882 mg.

\section{SIMPULAN}

Berdasarkan penelitiandapat disimpulkan bahwa daun jambu biji (Psidium guajava L.) dapat diformulasikan ke dalam sediaan krim. Formula yang menghasilkan sifat fisik lebih baik adalah formula 1 dengan konsentrasi asam stearat sebesar $14 \%$. Namun, pada formula 1 terdapat beberapa persyaratan sediaan krim yang belum terpenuhi seperti $\mathrm{pH}$, daya sebar, dan daya lekat sediaan krim. Pelepasan zat aktif kuersetin dari formula 1 selama 3 jam adalah 2,5882 mg.

\section{DAFTAR PUSTAKA}

Abdurraafi, M. Dermawan, L. Pratiwi, dan I. Kusharyanti. 2015. Efektivitas Krim Antijerawat Ekstrak Metanol Daun Pacar Air (Impatiens balsamina L.). Traditional Medicine Journal.20(3): 127-133.

Afifi, R. dan E. Erlin. 2017. Uji Anti Bakteri Ekstrak Daun Jambu Biji (Psidium guajava L) Terhadap Zona Hambat Bakteri JerawatPropionibacterium acnes Secara In Vitro. Jurnal Kesehatan Bakti Tunas Husada. 17(2): 321-330.

Ansel, H. C. 2008. Pengantar Bentuk Sediaan Farmasi. Edisi IV. Jakarta: Indonesia University Press.

Aqsha, A. C. 2016. Profil Pemilihan dan Penggunaan Produk Antijerawat yang Tepat pada Mahasiswa.Jurnal Farmasi Komunitas 3(1): 18-22.

BPOM RI.2012. Formulasium Ramuan Etnomedisin Obat Asli Indonesia.Volume II. Jakarta: Badan Pengawas Obat dan Makanan Republik Indonesia.

Depkes RI. 1979. Farmakope Indonesia. Edisi III. Jakarta: Departemen Kesehatan Republik Indonesia.

Depkes RI. 1995. Farmakope Indonesia.Edisi IV. Jakarta: Departeman Kesehatan Republik Indonesia.
Depkes RI. 2000. Parameter Standar UmumEkstrak Tumbuhan Obat. Jakarta: DepartemenKesehatan Republik Indonesia.

Genatrika, E., Nurkhikmah, I., Hapsari, I. 2016. Formulasi Sediaan Krim Minyak Jintan Hitam (Nigella sativa L.) Sebagai Antijerawat Terhadap Bakteri Propionibacterium acnes. Pharmacy13: 192-201.

Juliantoni, Y. dan Murford.2013. Formulasi Tablet Hisap Ekstrak Daun Jambu Biji (Psidium guajava L.) yang Mengandung Flavonoid dengan Kombinasi Bahan Pengisi Manitol-Sukrosa. Traditional Medicine Journal18(2): 103-108.

Kristanti, A. N., N. S. Aminah., M. Tanjung dan B. Kurniadi. 2008. Buku Ajar Fitokimia. Surabaya. Jurusan Kimia Laboratorium Kimia Organik FMIPA Universitas Airlangga.

Murtiningsih, S., S. N. Nurbaeti, dan I. Kusharyanti. 2014. Efektivitas Gel Antijerawat Ekstrak Metanol Daun Pacar Air (Impatiens balsamina L.) Terhadap Bakteri Propionibacterium acnes dan Staphylococcus epidermidis Secara In Vitro. Journal of Tropical Pharmacy and Chemistry 2(4): 225-234.

Saragih, D.f., H. Opod., C. Pali. 2016. Hubungan Tingkat Kepercayaan Diri dan Jerawat (Acne vulgaris) pada Siswa-siswi Kelas XII di SMA Negeri 1 Manado.Jurnal eBiomedik4(1): 1-6.

Yulianti, R. 2015. Formulasi Krim Anti Jerawat Kombinasi Ekstrak Daun Sirsak (Annona muricata L.) Dan Daun Jambu Biji (Psidium guajava L.). Jurnal Kesehatan Bakti Tunas Husada14(1): 158-161.

Yulisma, L. 2018. Uji Efektivitas Antibakteri Ekstrak Daun Jambu Biji Lokal (Psidium guajava L) Terhadap Pertumbuhan Staphylococcus aureus Dan Bacilus Subtilis Secara In Vitro. Quagga10(2): 16. 